\title{
Numerical 3D study on the influence of spanwise distribution of tubercles on wings for UAV applications
}

\author{
Charalampos Papadopoulos ${ }^{1, *}$, Vasilis Katsiadramis $^{2}$, and Kyros Yakinthos $^{1,2}$ \\ ${ }^{1} \mathrm{UAV}$ integrated Research Center (UAV-iRC), Center for Interdisciplinary Research and Innovation \\ (CIRI), Aristotle University of Thessaloniki, 57001, Thessaloniki, Greece \\ ${ }^{2}$ Laboratory of Fluid Mechanics and Turbomachinery, Department of Mechanical Engineering, \\ Aristotle University of Thessaloniki, Thessaloniki, 54124, Greece
}

\begin{abstract}
In this work, a 3D numerical study on the influence of the spanwise distribution of tubercles for UAV applications is presented. The idea of using tubercles in aeronautics comes from the humpback whale (Megaptera novaeangliae) which has a characteristic flipper, with a spanwise scalloped leading edge, creating an almost sinusoidal shape, consisting of bumps called tubercles. Early experimental research showed a great potential in enhancing the $3 \mathrm{D}$ aerodynamic characteristics of a wing. Most of the existing experimental results concern infinite wings (2D) models and are accompanied with substantial loss in lift and increase in drag in pre-stall region. On the other hand, finite models (3D) have displayed a better overall aerodynamic performance (increased lift and moment, but also decreased drag). At a range of Reynolds number between 500,000 and 1,000,000 (based on the mean chord of the flipper), tubercles act as virtual fences, introducing a pair of counter rotating vortices that delays the stall of the flipper, a phenomenon that the whales use to perform sharp turns and catch their prey. The aforementioned Reynolds number range is the same as the operational Reynolds number for typical Unmanned Aerial Vehicles (UAV). To assess the influence of the tubercles installation on UAV wings, a full 3D computational study is carried-out, with the use of CFD tools that at a first phase are validated and calibrated with available in the literature experimental data. Then, computations are performed, for different spanwise tubercles distributions. The results show that there is a noticeable potential on controlling the flow on the wings of a UAV operating in a Reynolds number range between 500,000 and $1,000,000$ (based on UAV's wing mean chord), which can lead to an aerodynamic performance and efficiency increase.
\end{abstract}

\section{Introduction}

In the last two decades, biomimetics has been an upcoming trend amongst aerodynamic designers, motivating several investigations into unusual body and wing shapes. These

\footnotetext{
* Corresponding author: charalpi@auth.gr
} 
studies get their inspiration from shapes and mechanisms found in nature and try to improve the aerodynamic behavior of aircraft. Passive flow control is a sector with great interest in biomimetics. Especially for UAVs and small, single seater aircraft, passive flow control is at an early stage of application with limited efficiency [1]. A characteristic example of the existing potential in biomimetics are the tubercles [Figure 1]. These spanwise protuberances create a sinusoidal leading edge and can be found on the flipper of the humpback whale (Megaptera novaeangliae). Equipped with tubercles, the whales achieve high maneuverability, despite their disproportionate size [2-3].

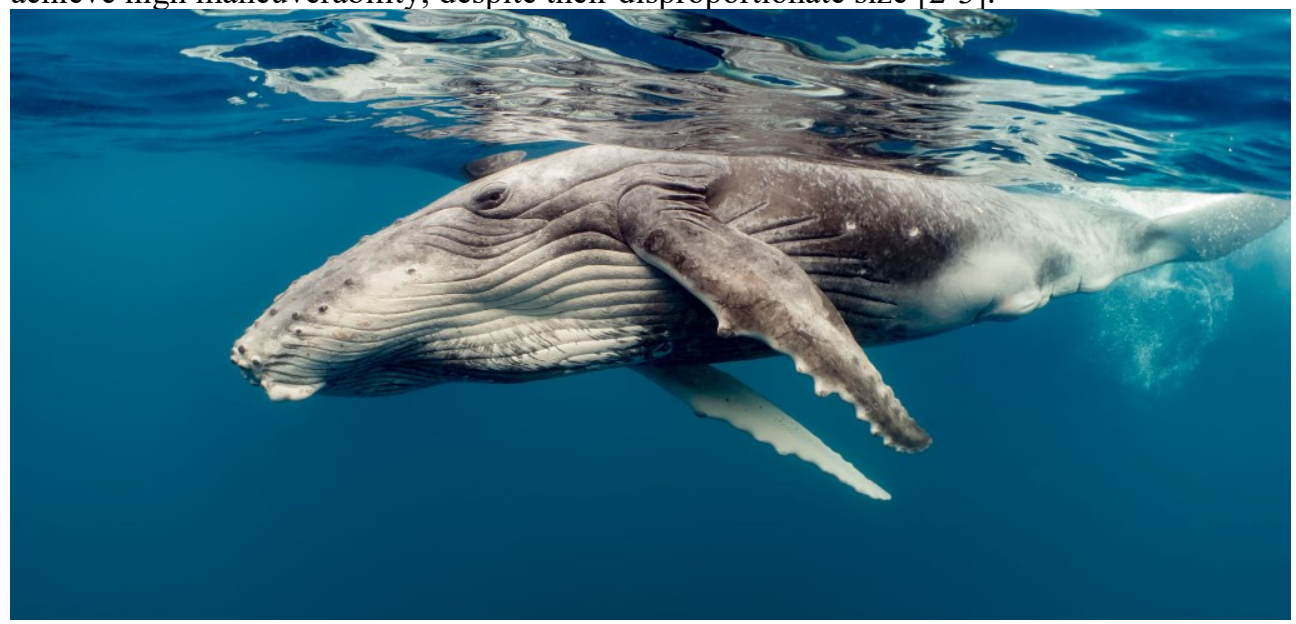

Fig. 1. A humpback whale and the tubercles that can be found on the leading edge of the flipper.

\subsection{Literature review}

In the early 2000's Miklosovic et al. [4] published a paper claiming that wings with tubercled leading edge could increase the generated lift while reducing drag, compared to a plain one. Johari [5] experimented with infinite wings and proved that the tubercled wing had reduced drag at post stall conditions. An explanation to these results was offered by Custodio [6], by introducing his understanding of the tubercles mechanism. Except the fact that each tubercle generates a pair of counter rotating vortices [7], it is still debated if tubercles act as vortex generators [4], if they compartmentalize the flow [8] or if they upwash the flow in the troughs and downwash it on the peaks [9]. Bolzon et al. [10] stated that these counter rotating vortices mix the low momentum boundary layer with the freestream. Thus, the flow is reenergized and remains attached for greater angles of attack (AoA).

While going through the literature it became apparent that a major difference exists between infinite and finite wing experiments [11]. The infinite wing tubercle experiments display substantial loss in lift and increase in drag in pre-stall region. In the post-stall region, they presented increased lift and moment with decreased drag. Furthermore, the post stall behavior can be characterized as smooth. On the other hand, finite wing tubercle experiments show not only increased lift and moment but also decreased drag, in both the pre- and post-stall region. Miklosovic et al. [12] claimed that the flow created by the sinusoidal leading edge reduced the effectiveness of the infinite wing by triggering early separation due to the vorticity. On the other hand, the effectiveness of the finite wing is enhanced by suspending the spanwise stall progression. Thus, the operating envelope of the finite wing is further improved with minimal performance penalties [12]. 
Due to the complexity and recency of this research topic, swept wings have not been the primary platform for testing tubercles. Instead, great emphasis has been given to infinite wing experiments and simulations [11]. Bolzon [10], while investigating experimentally the NACA 0021 airfoil at a sweep angle of 35 degrees and at a Reynolds number of 200,000, found a 3\% increase in the maximum lift to drag ratio. Wei et al. [13] repeated Bolzon's experiment and visualized with oil flow his results that were carried out in almost the same condition. However, the tubercled wing generated lower lift and higher drag values at prestall conditions. Finally, Abrantes et al. [14] also proved that tubercles at a Reynolds number of 200,000 can be beneficial to the aerodynamic performance of a swept wing with a NACA 0020 airfoil.

\subsection{Selected case}

After the literature review, it became evident that there is a relative scarcity of information regarding both experimental and numerical studies for tubercles at high Reynolds numbers [11], with most of the studies taking place at Reynolds number from 100,000 to 500,000. Furthermore, the few case studies with swept wings showcased seemingly contradictory results $[10,13,14]$, a result of insufficient research material. Given that the humpback whale also swims with its flippers at an average position of 20 degrees of sweep [15], the authors opted to study a swept wing at a relatively high Reynolds number of 1,000,000. This number is a characteristic value in a UAV flight, based on UAV's mean aerodynamic chord (MAC), but also approximately the same Reynolds number region as that of a whale swimming, based on the mean chord of the flipper.

The selected airfoil was the NACA 0021, an airfoil that has the same thickness ratio as the whale's flipper and roughly resembles it [11]. This airfoil has been extensively studied at low Reynolds regimes [10,16,18], but no results have been published for higher Reynolds numbers. Four different cases were studied [Figure 2]. All the wings had quarterchord sweep angle of $33^{\circ}$ and taper ratio of 0.61 . The root chord was $0.855 \mathrm{~m}$ and the wing span was $2.5 \mathrm{~m}$, producing a MAC of $0.7 \mathrm{~m}$.
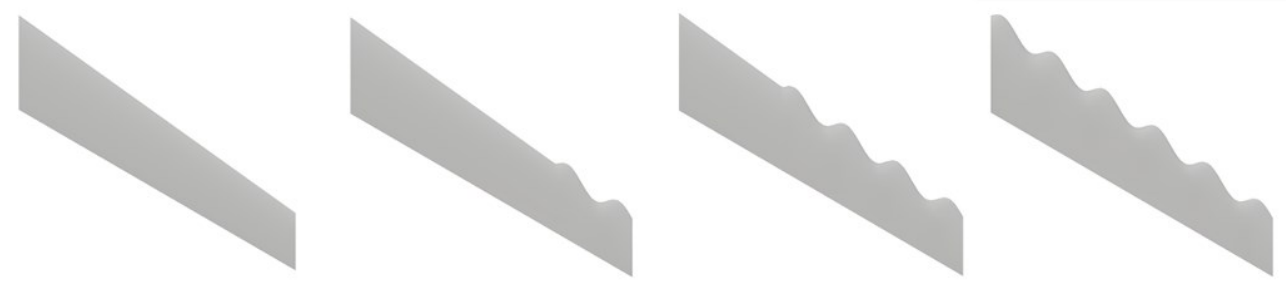

Fig. 2. The four cases that were chosen for this work.

The four different cases that were studied had varied spanwise distribution of tubercles; the baseline, the 0.33 span, the 0.67 span (whale-like) and the full span tubercled wing. Amplitude and frequency were $0.075 \mathrm{~m}$ and $0.455 \mathrm{~m}$ respectively. These values were the authors' choice and were adopted as an initial approach to the understanding of the complex aerodynamic phenomena of tubercles at high angles of attack.

\section{Methodology}

Grid dependency studies were carried out for all the selected validation and test cases of this work. All the meshes were constructed in the ANSA pre-processor of BETA CAE Systems. The simulations were carried out in the commercial code ANSYS Fluent (ANSYS@ Scientific Research, Release 18.2), using the Transition SST-4eq turbulence 
model, as it showed good accordance with lower Reynolds number literature cases [11]. Also, the second order discretization was used for the mean flow, turbulence and transition equations. Twenty inflation layers were generated in order to ensure that the boundary layer development is accurately modeled. It was ensured that $\mathrm{y}^{+}$values were approximately 1 , ensuring that the laminar and transitional boundary layers were accurately captured. For both the validation and test cases, all meshes were constructed with the same quality criteria.

In order to validate and calibrate the CFD setup, an experimental case was needed. Due to the lack of 3D high Reynolds number experiments, the authors decided to validate the CFD setup at a lower Reynolds number for both an infinite and a finite wing case, to ensure that the complex phenomena inserted by tubercles are completely captured. For the infinite wing case, the experimental results of Johari [17] at the 450,000 Reynolds number were used. For the finite wing case, the experiment of Bolzon [18] was utilized in order to test the CFD setup at the Reynolds number of 225,000. The literature geometries and flow boundary conditions were duplicated as best as possible.
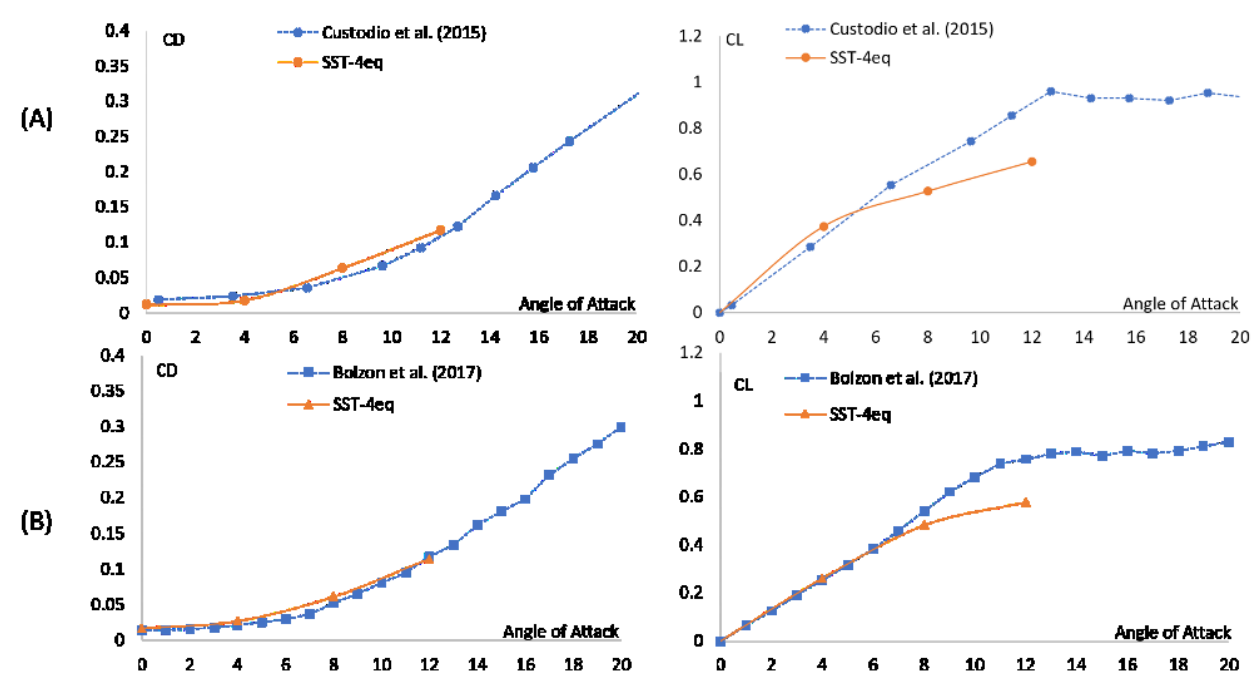

Fig. 3. The comparison between the literature [17-18] and the numerical results for the infinite wing (A) and the finite wing (B) cases.

The results of the calibration and validation showed good accordance with the experimental data [Figure 3A, 3B]. This proves that the Transition SST-4eq turbulence model is good at capturing the phenomena associated with tubercles and it is in good agreement with findings from other researchers that used the same turbulence model [11]. An underprediction of lift coefficient values at high angles of attack can be observed. The same deviation between experimental values and numerical computations was also noted by Dropkin [19] and was attributed to the inability of the turbulence model to correctly predict laminar separation. To capture the highly unsteady nature of the flow at such regimes it is suggested to use computational models like LES or Unsteady RANS. However, the increased requirement for computational power and the fact that UAVs and small aircraft do not usually cruise at high angles of attack, make this trade-off not unnecessary.

After the validation was concluded, the authors continued with the under-research geometry. Regarding the turbulence parameters, the length scale and the turbulence intensity for the free stream values were set to $0.2 \mathrm{~m}$ and $1 \%$ respectively, based on the earlier validation with the experimental results. The computational grid for the 0.67 
spanwise case test case, shown in Figure 4, consisted of approximately 11,300,000 computational elements and is an indicative depiction of all meshes.

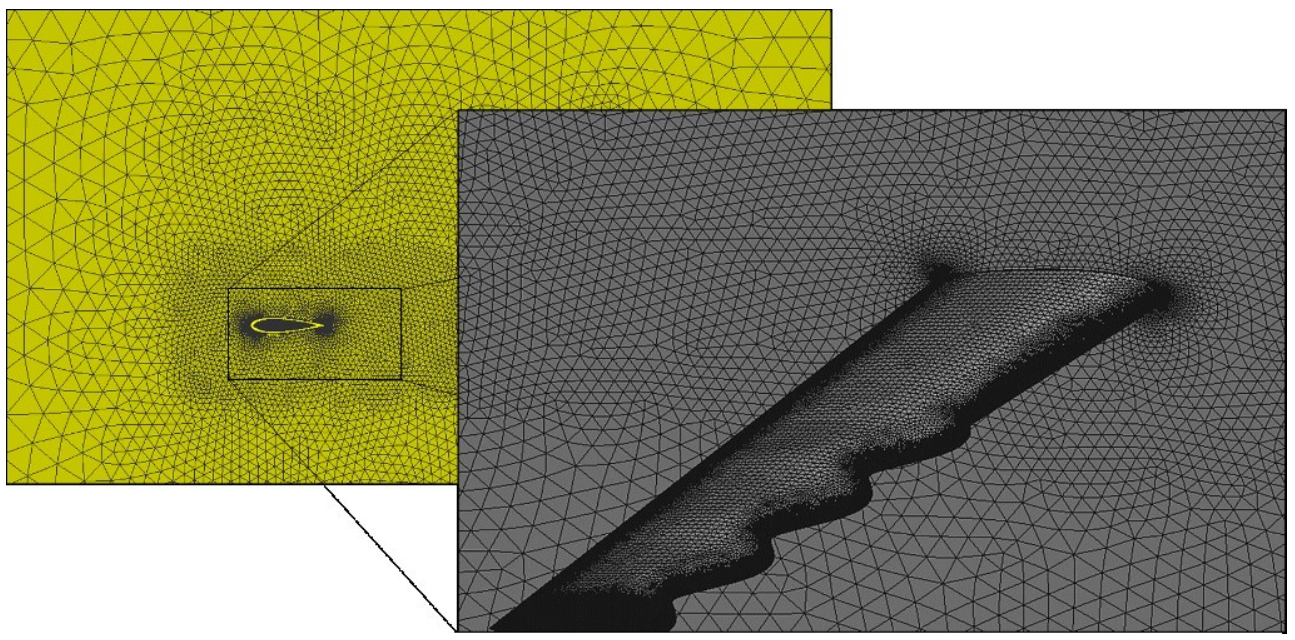

Fig. 4. Computational grid on the surface of the 0.67 span tubercled wing.

\section{Results}

Figure 5 presents the calculated lift and drag coefficients for all wing cases at the selected Reynolds number. The angle of attack ranged from $0^{\circ}$ to $12^{\circ}$ with a $\Delta$ a step of $2^{\circ}$. As seen in Figure 5 (left), the gradient of the lift $(\mathrm{dCL} / \mathrm{dAoA})$ is the largest for tubercles located along full span, whereas, the smallest for the baseline model. Also, a constant percentile difference in the range of 4-12 AoA can be observed. The full span model generates $9 \%$ more lift in comparison with the baseline model, while the 0.33 span and 0.67 models generate $5 \%$ more lift compared to the baseline model.
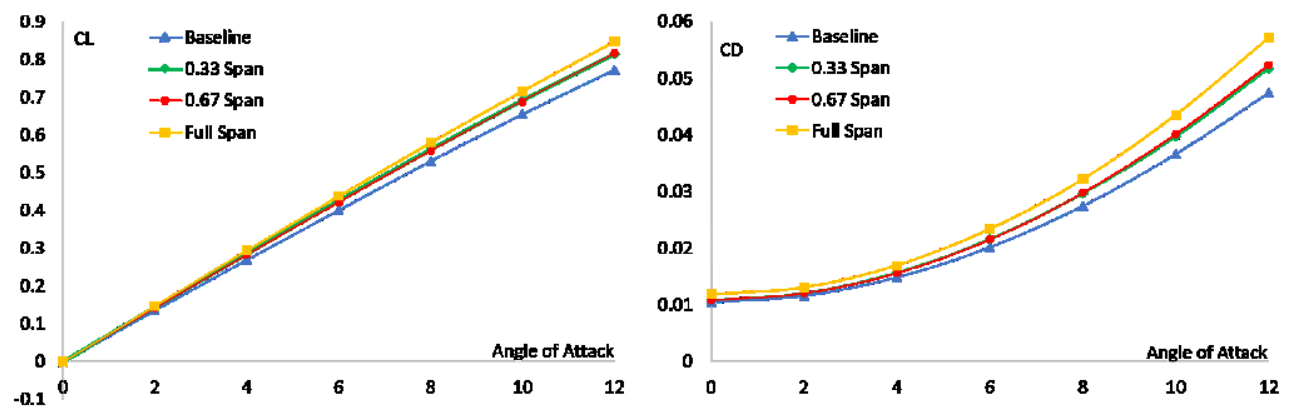

Fig. 5. Coefficient of lift (left) and drag (right) for all the studied cases.

On the contrary, the addition of tubercles does not affect positively the drag coefficient as illustrated in Figure 5 (right). Throughout the examined range of AoAs, the full span model exhibits the highest values of drag coefficient. Again, the 0.33 span and 0.67 span models have identical values. The baseline model has the lowest values between the tested cases at all AoAs. Only above $\mathrm{AoA}=4^{\circ}$ become the differences between the examined cases noticeable. The higher drag values can de attributed to the increased induced drag that the modified wings exhibit. 

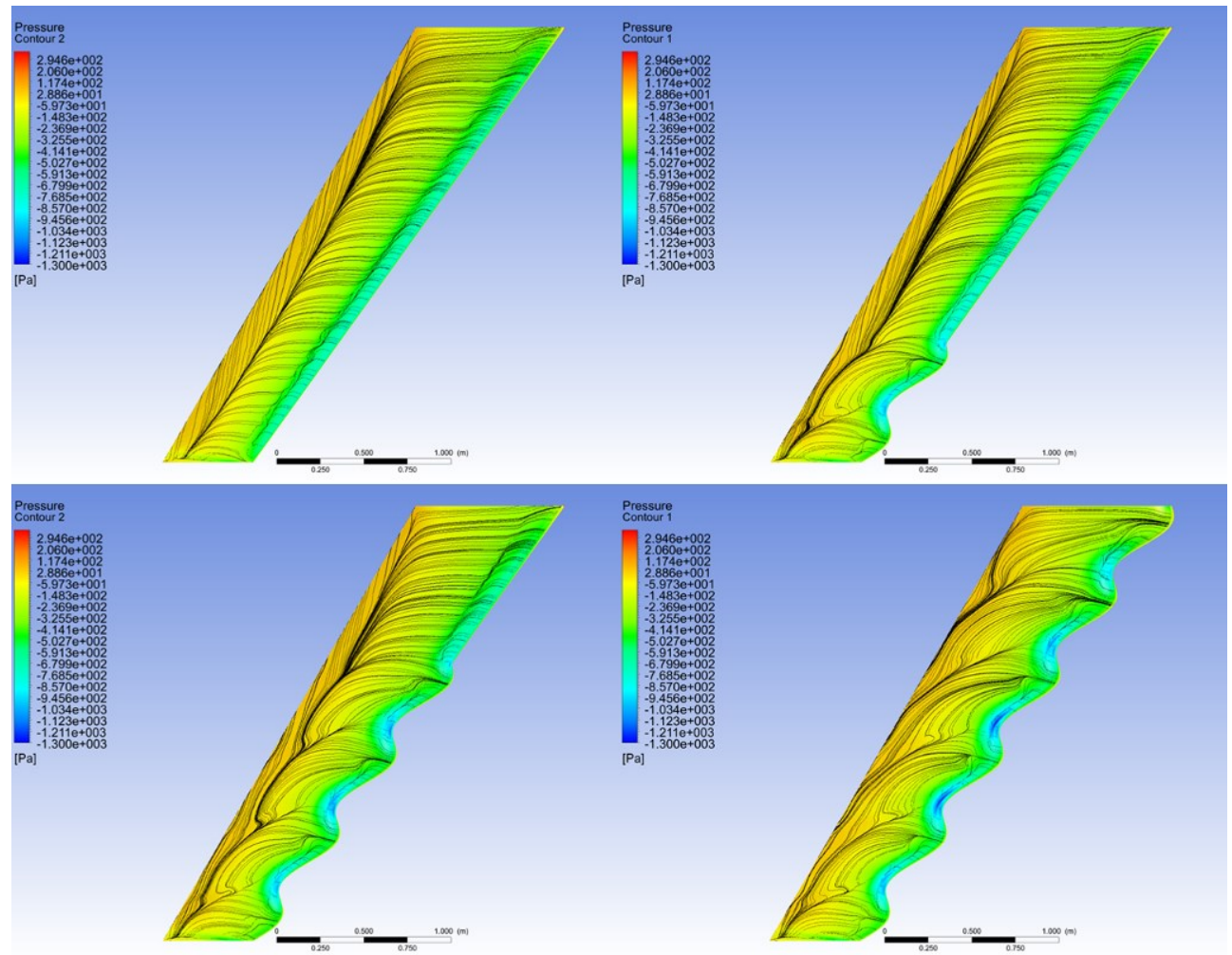

Fig. 6. Pressure distribution and streamlines on top of the upper surface of the wings at $A o A=12^{\circ}$.

As seen in Figure 6, the leading edge protuberances modify the flow over the wing surface. The figure depicts the changes in pressure distribution, and as a result, the changes in the acting forces, over the suction side of the wings caused by the insertion of tubercles. In the modified models the lowest pressure is located in the troughs, while over the peaks is higher. The lack of streamlines in the troughs indicates that the flow is detached, while the flow over the peak is attached. It can be observed, that the separation bubble in the baseline model is significantly larger, compared to the other cases. As a result, the addition of tubercles suppresses the development of the separation. This can be attributed to the pair of streamwise vortices that each tubercle produces.

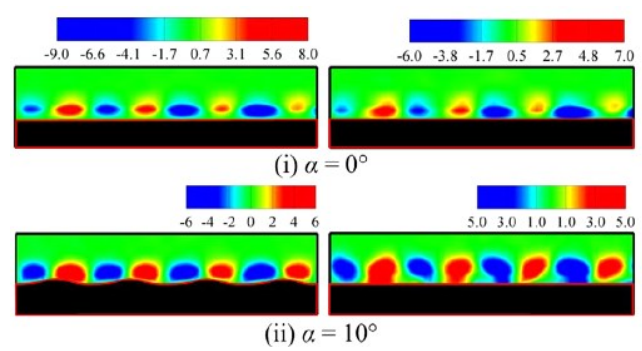

2D - No sweep

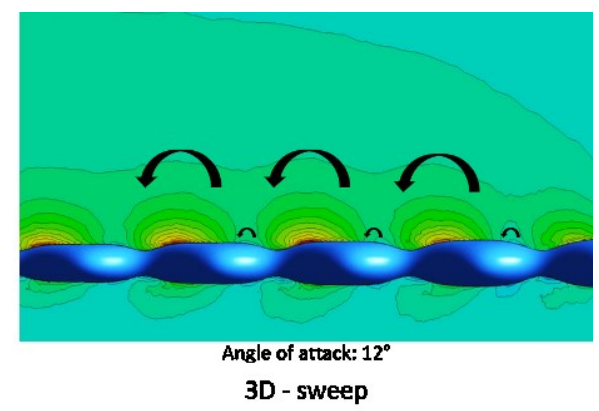

Fig. 7. The difference in the rotation for a typical infinite wing case [20] and a swept tubercled wing. Various infinite wing investigations [20] have shown that tubercles produce a pair of counter rotating vortices that modifies the flow over the airfoils. However, Figure 7 shows that in a swept wing the pair of counter rotating vortices transforms into a pair of co- 
rotating vortices. Due to the spanwise flow coming from the wing sweep, one vortex becomes stronger and larger, while the other one diminishes.

\section{Conclusions}

Four swept wings were modelled with different spanwise distributions of tubercles at a Reynolds number of $1,000,000$. The results showed that the addition of tubercles increases the lift throughout the selected angle of attack range, and this outlines the potential of tubercles as an effective passive flow control method. However, tubercles have a negative effect on drag in the pre stall regime. The leading edge protuberances affect the flow over the wing and therefore the pressure distribution. Due to the pair of co-rotating vortices that is produced by each tubercle and mixes the boundary layer with the freestream, the flow remains attached over a greater area of the swept wing and the size of the separation bubble becomes smaller. Furthermore, the tubercles restrict the spanwise flow.

The increase on lift in the modified wings is a motivating result at a first place. However, more studies need to be carried out with different amplitudes and wavelengths, in order to optimize the shape of the protuberances, so as to achieve lower values of drag and more aerodynamically efficient wings. More experiments should also be conducted at higher Reynolds numbers, as the lack of experimental data makes numerical validation more difficult at this Reynolds number regime.

\section{References}

1. Panagiotou, P., P. Kaparos, K. Yakinthos. Winglet design and optimization for a MALE UAV using CFD, Aerospace Science and Technology 39 (2014): 190-205.

2. Fish, Franke E., and Juliann M. Battle, Hydrodynamic design of the humpback whale flipper, Journal of Morphology 225.1 (1995): 51-60.

3. Fish, Frank E., Laurens E. Howle, and Mark M. Murray, Hydrodynamic flow control in marine mammals, Integrative and Comparative Biology 48.6 (2008): 788-800.

4. Miklosovic, D. S., Murray, M. M., Howle, L. E., and Fish, F. E., Leading-edge tubercles delay stall on humpback whale (Megaptera novaeangliae) flippers, Physics of fluids, 16(5), (2004), L39-L42.

5. Johari, Hamid, Charles W. Henoch, Derrick Custodio, and Alexandra Levshin, Effects of leading-edge protuberances on airfoil performance, AIAA journal 45, no. 11 (2007): 2634-2642.

6. Custodio, Derrik, The Effect of Humpback Whale-like Leading Edge Protuberances on Hydrofoil Performance, sl: Worcester Polytechnic Institute, 2007. Diss. Masters Thesis, 2007.

7. Hansen, Kristy Lee, Effect of leading edge tubercles on airfoil performance, Diss. 2012.

8. Watts, Phil, and Frank E. Fish, The influence of passive, leading edge tubercles on wing performance, Proc. Twelfth Intl. Symp. Unmanned Untethered Submers. Technol. Durham New Hampshire: Auton. Undersea Syst. Inst., 2001.

9. Van Nierop, Ernst A., Silas Alben, and Michael P. Brenner, How bumps on whale flippers delay stall: an aerodynamic model, Physical review letters 100.5 (2008): 054502.

10. Bolzon, M. D., R. M. Kelso, and M. Arjomandi, The effects of tubercles on swept wing performance at low angles of attack, Proceedings of the 19th Australasian Fluid 
Mechanics Conference. Australasian Fluid Mechanics Soc. Melbourne, Australia, 2014.

11. Aftab, S. M. A., N. A. Razak, AS Mohd Rafie, and K. A. Ahmad, Mimicking the humpback whale: An aerodynamic perspective, Progress in Aerospace Sciences 84 (2016): 48-69.

12. Miklosovic, David S., Mark M. Murray, and Laurens E. Howle, Experimental evaluation of sinusoidal leading edges, Journal of aircraft 44.4 (2007): 1404-1408.

13. Wei, Zhaoyu, Tze How New, and Y. D. Cui, Aerodynamic performance and surface flow structures of leading-edge tubercled tapered swept-back wings, AIAA Journal (2017): 423-431.

14. Abrantes, Thiago Thadeu D., Alejandro A. Rios Cruz, Adson A. de Paula, Vitor G. Kleine, and Felix Büttner, The wing three-dimensional effects on wavy leading edge performance, In 35th AIAA Applied Aerodynamics Conference, p. 4467. 2017.

15. Fish, Franke E., and Juliann M. Battle, Hydrodynamic design of the humpback whale flipper, Journal of Morphology 225.1 (1995): 51-60.

16. Bolzon, Michael D., Richard M. Kelso, and Maziar Arjomandi, Tubercles and their applications, Journal of Aerospace Engineering 29.1 (2015): 04015013

17. Custodio, Derrick, C. W. Henoch, and Hamid Johari, Aerodynamic characteristics of finite span wings with leading-edge protuberances, AIAA journal 53.7 (2015): 18781893.

18. Bolzon, Michael D., Richard M. Kelso, and Maziar Arjomandi, Force measurements and wake surveys of a swept tubercled wing, Journal of Aerospace Engineering 30.3 (2017): 04016085.

19. Dropkin, A., D. Custodio, C. W. Henoch, and H. Johari, Computation of flow field around an airfoil with leading-edge protuberances, Journal of Aircraft 49, no. 5 (2012): 1345-1355.

20. Wei, Zhaoyu, T. H. New, and Y. D. Cui, An experimental study on flow separation control of hydrofoils with leading-edge tubercles at low Reynolds number, Ocean Engineering 108 (2015): 336-349. 